Conference abstract L01

\title{
Drug Delivery in the GI Tract: How Controlled is Controlled Release?
}

\author{
W. WeITSCHIES
}

Department of Biopharmaceutics and Pharmaceutical Technology, Institute of Pharmacy, University of Greifswald, Germany

E-mail: werner.weitschies@uni-greifswald.de

Sci Pharm. 2010; 78: 541

doi:10.3797/scipharm.cespt.8.L01

There is very often a great gap between the performance of oral drug delivery systems in vitro and in vivo. During the last decade modern high resolution and/or real time imaging techniques like Magnetic Marker Monitoring (MMM) [1] or Magnetic Resonance Imaging (MRI) [2,3] have provided new insights into the in vivo performance of drug delivery systems and their interaction with the physiology of the gastrointestinal tract. The physiological conditions for drug absorption along the gastrointestinal tract are far from being constant. This applies to the expression of transport proteins and metabolizing enzymes as well as for the luminal conditions [3, 4]. Accordingly, gastrointestinal passage of a drug delivery system plays a crucial role for drug absorption. Gastrointestinal transit is also not a constant process. It is strongly controlled by feedback mechanisms that involve neuronal and hormonal signal pathways. In contrast to widespread assumption, transit times through all gastrointestinal organs, i. e. stomach, small intestine and colon, are highly variable. Gastric residence times are in general dependent on the energy content of the gastric filling. The rate of gastric emptying under fed conditions is controlled by the energy content of the meal, the energy requirement of the body and feedback mechanisms like the ileal brake mechanism. Furthermore, the rate of gastric emptying under fed conditions is also influenced by particle size. As a consequence, the emptying of drug substances from the digesting stomach is dependent on three main factors, the gastric emptying rate of the meal, the intragastric distribution of the drug and the particle size of the formulation. Examples for the in vivo behavior of different oral controlled release systems and resulting drug plasma concentration profiles will be shown and discussed.

[1] Weitschies W, Blume H, Mönnikes H. Magnetic marker monitoring: high resolution real-time tracking of oral solid dosage forms in the gastrointestinal tract. Eur J Pharm Biopharm. 2010; 74: 93-101.

doi:10.1016/j.ejpb.2009.07.007

[2] Faas H, Schwizer W, Feinle C, Lengsfeld H, de Smidt C, Boesiger P, Fried M, Rades T. Monitoring the intragastric distribution of a colloidal drug carrier model by magnetic resonance imaging. Pharm Res. 2001; 18: 460-466. doi:10.1023/A:1011098125916

[3] Schiller C, Fröhlich CP, Giessmann T, Siegmund W, Mönnikes H, Hosten N, Weitschies W. Intestinal fluid volumes and transit of dosage forms as assessed by magnetic resonance imaging. Aliment Pharmacol Ther. 2005; 22: 971-979. doi:10.1111/j.1365-2036.2005.02683.x

[4] Englund G, Rorsman F, Rönnblom A, Karlbom U, Lazorova L, Grasjö J, Kindmark A, Artursson P. Regional levels of drug transporters along the human intestinal tract: co-expression of ABC and SLC transporters and comparison with Caco-2 cells. Eur J Pharm Sci. 2006; 29: 269-227. doi:10.1016/j.ejps.2006.04.010 